\title{
PLANO INTEGRADO DE FORMAÇÃO DESIGN-DRIVEN PARA SISTEMAS PRODUTIVOS LOCAIS
}

\author{
RONALDO MARTINS GLUFKE, DR. | UFSM/UNIFI \\ GIUSEPPE LOTTI, DR. | UNIFI
}

PALAVRAS-CHAVE: Plano Integrado. Formação. Design-Driven Sistemas Produtivos. Cerâmica de Revestimento. Território.

Com base em prognósticos mundiais, o Brasil apresenta uma possibilidade de incremento em sua produção do setor de revestimentos cerâmicos (ANFACER, 2016). Sendo a Itália uma das líderes e, referência neste segmento, com um produto de alto valor agregado fruto de design aplicado em sua cadeia de desenvolvimento e produção (KIECKBUSCH e LOPES, 2005), devemos então atentar-nos para a necesidade de capacitação e formação específica dos profissionais brasileiros buscando suprir as demandas de recursos humanos deste e de outros setores produtivos.

A formação de profissionais de Design no Brasil tem sido, por muito tempo e até atualmente, uma formação de base genérica, contudo, a especificidade setorial baseada na aplicação de conhecimentos diretos para setores produtivos e seus territórios, faz-se cada vez mais necessária, onde o uso de modelos didáticos de formação direcionados aparece como uma demanda latente a ser considerada.

Com o objetivo de suprir esta demanda, a proposta de um Plano Integrado de Formação, busca atender às necessidade setoriais e territoriais no que diz respeito a capacitação e formação de recursos humanos para atuarem nos setores produtivos de bens e serviços, foi realizada uma pesquisa de abordagem quanti-qualitativa, aplicada e exploratória, envolvendo estudos teóricos que resultaram em uma análise territorial abrangendo o território da Toscana, na Itália, e quatro estados da região Sul e Sudeste do Brasil, levantando aspectos comparativos no que diz respeito ao Design e sua formação além de mercados produtores e consumidores de bens e serviços.

Norteada por aspectos e conceitos do Design-Driven italiano (VERGANTI, 2013 e BRANZI, 1999), a pesquisa considerou ainda uma análise das necessidade de recursos humanos, apontada pelas empresas produtoras de bens e serviços de diversos setores da cadeia produtiva e por profissionais atuantes no segmento de desenvolvimento de produtos destes setores, como pode ser visto na Figura 1.

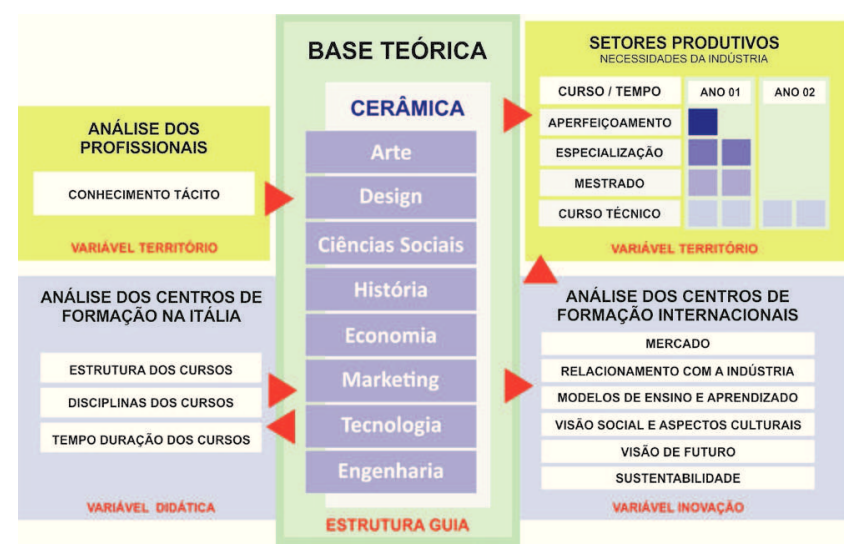

Figura 01: Arquitetura da pesquisa.

Fonte: Elaborado pelos autores.

A estruturação de uma base teórica sobre a cerâmica de revestimento considerou aspectos históricos, artísticos, técnicos e aplicativos, associada a análise de atividades e experiências de Centros formadores de profissionais em Design na Itália, da qual formou-se um panorama sobre modelos, conteúdos, duração e atividades didáticas e de uma análise de Centros formadores de profissionais em Design de outros países, que proporcionaram uma visão de futuro sobre a formação em Design, permitindo a reunião e sistematização destes conhecimentos, procedimentos e tecnologias, em a possibilidade para o desenvolvimento de um modelo de formação profissional 
versátil, a ser aplicado em setores produtivos e territórios diversos. A Aplicação do Modelo Didático desenvolvido na pesquisa foi direcionada, por vocação produtiva aos setores da náutica na região da Toscana e de cerâmica de revestimentos nas regiões Sul e Sudeste do Brasil, como mostra a Figura 2.

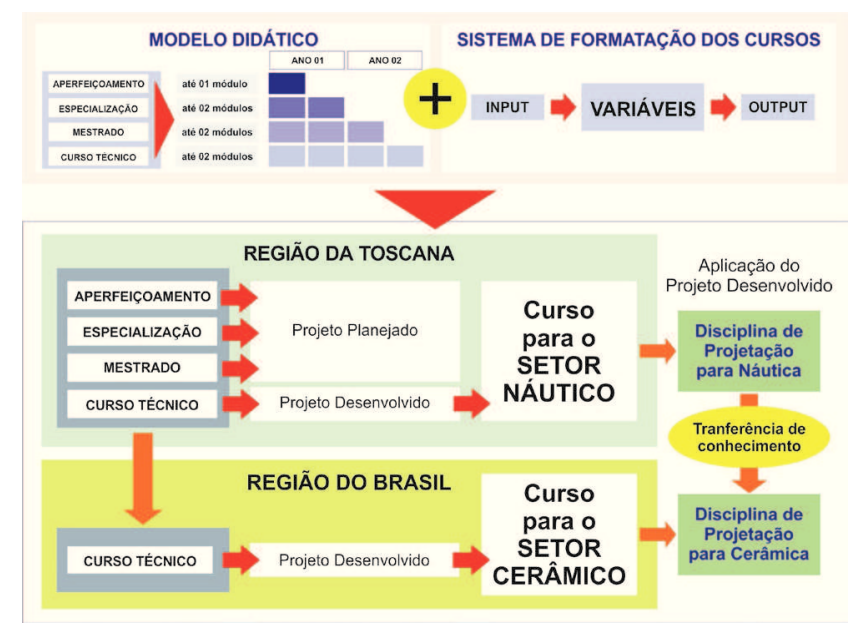

Figura 02: Aplicação do Modelo Didático.

Fonte: Elaborado pelos autores.

Os dados coletados e suas análises forneceram parâmetros para a estruturação de um Modelo Didático passível de aplicação em diversos níveis de formação, e adaptável às necessidades específicas de territórios e setores produtivos, contribuindo para a formação de um profissional qualificado a planejar, desenvolver e produzir produtos e processos de melhor qualidade, resultando no incremento produtivo e valor agregado de bens e serviços (Figura 3).

Figura 03: Estrutra do Modelo Didático.

Fonte: Elaborado pelos autores.

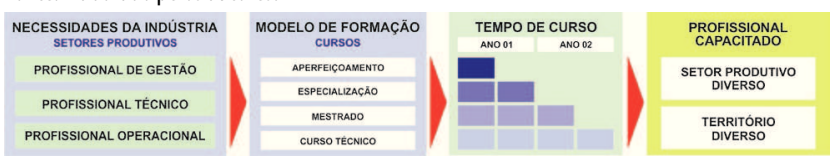

A capacidade de adaptação do Plano Integrado de Formação Design-Driven para Sistemas Produtivos Locais às necessidades formativas de territórios diversos podem possibilitar a transferência de conhecimento do Design aplicado e da experiência dos setores produtivos estudados.

\section{REFERÊNCIAS}

ANFACER. Panorama Geral. Em: <https://www.anfacer.org.br/mundial>. Acesso em agosto de 2016.
BRANZI, Andrea. Introduzione al Design Italiano: una modernità incompleta. Milão: Baldini Castoldi Dalai editora S.p.A., 2008.

\section{KIECKBUSCH, R. E.; LOPES, F. P. Diagnóstico Setorial} da Cerâmica para Revestimento Catarinense. IEL Instituto Euvaldo Lodi, SC, 2005. In: < www.portalbmk. org.br/publicacoes/arquivos/1134762800.pdf >. Acesso em março de 2013.

VERGANTI, Roberto. Gestire I'Innovazione DesignDriven. In: ZURLO, Francesco [et al]. Innovare con il design: Il caso del settore dell'illuminazione in Italia. Sistema Design Italia. Milão: II Sole 24 Ore S.p.A., 2002. 